\title{
Cobalt phosphide nanocage@ferric-zinc mixed-metal phosphide nanotube hierarchical nanocomposites for enhanced overall water splitting
}

\author{
Xiaowei Hu a, Yongheng Yin a, Wei Liu a, Xingwang Zhang b,*, Hongxiu Zhang a,\# \\ a Key Laboratory of Functional Nanomaterials and Technology in Universities of Shandong, School of Chemistry and Chemical Engineering, \\ Linyi University, Linyi 276005, Shandong, China \\ ${ }^{\mathrm{b}}$ Key Laboratory of Biomass Chemical Engineering of Ministry of Education, College of Chemical and Biological Engineering, Zhejiang University, \\ Hangzhou 310027, Zhejiang, China
}

\section{A R T I C L E I N F O}

Article history:

Received 29 November 2018

Accepted 9 January 2019

Published 5 July 2019

\section{Keywords:}

Hierarchical structure

Phosphide

Electrocatalysis

CoP@ZnFeP

Water splitting

\begin{abstract}
A B S T R A C T
Hierarchical nanostructures have attracted widespread interest owing to their unique properties compared to their bulk counterparts. Thus, they are considered promising electrocatalytic materials. In this work, a novel hierarchical porous nanocomposite of cobalt phosphide nanocage@ferric-zinc mixed-metal phosphide nanotubes (denoted CoP@ZnFeP) was fabricated using a self-assembly approach. Because of their structural and compositional merits, the as-prepared phosphide hybrids have abundant catalytic active sites and high porosity for facile mass diffusion. In an alkaline electrolyte, the CoP@ZnFeP flower-like hybrids displayed enhanced catalytic activity for the hydrogen evolution reaction and the oxygen evolution reaction compared with a mechanical mixture of $\mathrm{CoP}$ and $\mathrm{ZnFeP}$ nanoparticles. The CoP@ZnFeP hierarchical nanocomposites also showed excellent activity for the overall water splitting reaction, yielding a water-splitting current of $10 \mathrm{~mA} / \mathrm{cm}^{2}$ on the application of just $1.6 \mathrm{~V}$, as well as excellent durability (24-h long-term operation) in a two-electrode system. Our design methodology may create opportunities to search for highly efficient and robust non-precious metal catalysts with applications in high-performance energy conversion and storage devices.
\end{abstract}

(C) 2019, Dalian Institute of Chemical Physics, Chinese Academy of Sciences. Published by Elsevier B.V. All rights reserved.

\section{Introduction}

The energy crisis and environmental problems have increased the urgency for the development of renewable energy sources. Hydrogen is considered one of the most promising candidates because of its high energy density and non-polluting characteristics [1]. Among the many different hydrogen production technologies, water splitting is an appealing technique for energy conversion and storage, functioning by converting solar or wind-derived electricity to hydrogen fuel [2-4]. At present, challenges remain in commercialized water electrolysis systems. The practical applications of water-splitting are very limited because splitting reactions, including the anodic oxygen evolution reaction (OER) and cathodic hydrogen evolution reaction (HER), are all strongly uphill reactions with large overpotentials (actual cell voltage is $1.8-2.4 \mathrm{~V}$, whereas the thermodynamic value is $1.23 \mathrm{~V}$ ) [5]. Therefore, it is urgent and meaningful to explore efficient electrocatalysts for the water

\footnotetext{
* Corresponding author. Tel/Fax: +86-571-87952525; E-mail: xwzhang@zju.edu.cn

\# Corresponding author. Tel/Fax: +86-539-7258620; E-mail: zhanghongxiu@lyu.edu.cn

This work was supported by the Natural Science Foundation of Shandong Province (ZR2018BB061, ZR2018BB060, ZR2018LB004).

DOI: S1872-2067(19)63299-7 | http://www.sciencedirect.com/science/journal/18722067 | Chin. J. Catal., Vol. 40, No. 7, July 2019
} 
splitting system. Noble metal (Pt or Ir)-based catalysts have long been the benchmarking materials for HER and OER, but they are costly and scarce. Therefore, the design and construction of efficient bifunctional catalysts via the exposure of more HER and OER catalytically active sites simultaneously in the same electrolyte (alkaline, acid, or neutral) are urgently needed and remain a challenge. Currently, low-cost earth-abundant transition metal compounds have been developed as possible alternatives, especially for use in alkaline electrolytes [6,7].

To date, some non-noble metal-based bifunctional catalysts have been thoroughly explored in alkaline electrolytes [8,9], including transition-metal based sulfides (e.g., $\mathrm{NiCo}_{2} \mathrm{~S}_{4}$ and $\mathrm{Ni}_{3} \mathrm{~S}_{2}$ ) [10,11], oxides (e.g., $\mathrm{NiCo}_{2} \mathrm{O}_{4}$ ) [12], layered double hydroxides (LDH) (e.g., NiFe LDHs) [13-16], carbides [17], nitrides [18], and phosphides [19-21]. It should also be mentioned that the catalytic performances of these non-noble-metal-based nanomaterials have not been maximized, and, overall, the water splitting reaction still suffers from a high overpotential and sluggish reaction rate. Among the earth-abundant transition metal compounds, the transition metal phosphides have been intensively studied and are promising candidates for overall water splitting reaction [8,22,23]. Previous studies have indicated that optimizing the nanostructure and composition of the catalysts is key to maximizing the catalytic efficiency [24]. In the past decades, materials based on a metal-organic framework (MOF) have been shown to provide a suitable platform for designing porous nanostructure catalysts for water splitting because of their high metal content, ultra-high porosity, high specific surface areas, tunable pore structures, and easily functionalized surfaces $[25,26]$. Inspired by these diverse configurations, MOF materials have been widely used in many fields, including gas storage/separation and chemical sensors [27-29]. More importantly, they serve as appealing sacrificial precursors or templates to prepare functional materials [30-32]. However, the design of transition metal phosphides derived from multi-component MOF structures as water splitting catalysts is still rarely reported.

Herein, we report a stepwise strategy to design and fabricate novel hierarchically porous cobalt phosphide nanocage@ferric-zinc mixed-metal phosphide nanotubes (CoP@ZnFeP) hollow nanocomposites derived from MOF precursors as overall water splitting electrocatalysts. The hierarchical structures are composed of CoP nanocages and $\mathrm{ZnFeP}$ nanotubes. The as-prepared flower-like CoP@ZnFeP hybrids show remarkable electrocatalytic activity for the HER and OER in $1.0 \mathrm{~mol} / \mathrm{L} \mathrm{KOH}$ electrolyte, having onset overpotentials of

50 and $148 \mathrm{mV}$ and Tafel slopes of 76 and $53.9 \mathrm{mV} /$ decade, respectively. The CoP@ZnFeP flower-like hybrids display enhanced catalytic activity compared with the mechanical mixture of $\mathrm{CoP}$ and $\mathrm{ZnFeP}$ particles. Importantly, the catalytic performance is comparable to that of commercial noble-metal catalysts. The CoP@ZnFeP hierarchical nanocomposites also show excellent activity toward overall water splitting, yielding a $10 \mathrm{~mA} / \mathrm{cm}^{2}$ water-splitting current on the application of just 1.6 V (24-h continuous galvanostatic electrolysis) in the two-electrode system. The excellent performance is mainly due to the nano-building-blocks (nanocages, nanoparticles, and nanotubes), which have a large surface area and well-defined porous channels that are advantageous for mass and charge transport in the electrolyte. This design methodology for mixed-metal phosphides derived from MOFs may create the opportunities to search for highly efficient and robust non-precious metal catalysts for applications in high-performance energy conversion and storage devices.

\section{Experimental}

\subsection{Sample preparation}

The $\mathrm{Co}_{3} \mathrm{O}_{4}$ nanocages were prepared according to a previously reported method [33]. In a typical synthesis, two solutions were first prepared. Solution A contained $1 \mathrm{mmol}$ $\mathrm{Co}\left(\mathrm{NO}_{3}\right)_{2} \cdot 6 \mathrm{H}_{2} \mathrm{O}$ dissolved in $10 \mathrm{~mL}$ distilled water with stirring, and solution $\mathrm{B}$ contained $\mathrm{K}_{3}\left[\mathrm{Co}(\mathrm{CN})_{6}\right]_{2}(0.04 \mathrm{mmol})$ and polyvinylpyrrolidone (PVP) surfactant $(0.3 \mathrm{~g})$ dissolved in $10 \mathrm{~mL}$ distilled water. The transparent red solution A was slowly added to solution B and aged for $24 \mathrm{~h}$ at room temperature. The resulting precipitate was washed several times with distilled water and ethanol, respectively, and then dried overnight at $60{ }^{\circ} \mathrm{C}$ under vacuum. The resulting powder was finally decomposed at $400{ }^{\circ} \mathrm{C}$ for $1 \mathrm{~h}$ in a $\mathrm{N}_{2}$ atmosphere in an oven. All chemicals were of analytical purity and used without further purification.

The hierarchical $\mathrm{Co}_{3} \mathrm{O}_{4} @ \mathrm{Fe}-\mathrm{MOF}-5$ nanocomposites were prepared according to our previously reported method [34]. In a typical procedure, $\mathrm{Co}_{3} \mathrm{O}_{4}$ nanocages $(25 \mathrm{mg}), \mathrm{Fe}(\mathrm{acac})_{3}(75$ $\mathrm{mg}$ ), $\mathrm{Zn}\left(\mathrm{NO}_{3}\right)_{2} \cdot 6 \mathrm{H}_{2} \mathrm{O}$ (58 mg), and benzene-1,4-dicarboxylic acid $\left(\mathrm{H}_{2} \mathrm{BDC}, 2 \mathrm{mg}\right)$ were dissolved in dimethylformamide (DMF)/ethanol solution ( $2 \mathrm{~mL}, v / v=5 / 3$ ). This solution was treated using ultrasonic waves for $30 \mathrm{~min}$. The mixed solution was transferred to a 50-mL Teflon-lined autoclave and heated at $100{ }^{\circ} \mathrm{C}$ for $6 \mathrm{~h}$. After cooling to room temperature, the hierarchical $\mathrm{Co}_{3} \mathrm{O}_{4} @ \mathrm{Fe}-\mathrm{MOF}-5$ nanocomposites were obtained after centrifugation and washing several times with distilled water and ethanol, successively, followed by drying overnight (12 h) at $50{ }^{\circ} \mathrm{C}$ in a vacuum. For comparison purposes, Fe-MOF- 5 was also prepared in the absence of $\mathrm{Co}_{3} \mathrm{O}_{4}$ nanocages in the DMF/ethanol solution.

The hierarchical CoP@FeZnP nanocomposites were prepared by phosphorization. In a typical procedure, a $\mathrm{Co}_{3} \mathrm{O}_{4} @ \mathrm{Fe}-\mathrm{MOF}-5$ sample was placed in the center of a tube furnace, and a combustion boat containing $\mathrm{NaH}_{2} \mathrm{PO}_{2}(0.2 \mathrm{~g})$ was placed in the upstream side of the quartz tube. Before heating, the tube was flushed with Ar. The center of the furnace was slowly elevated to $400{ }^{\circ} \mathrm{C}$ (heating speed $=1{ }^{\circ} \mathrm{C} / \mathrm{min}$ ) under the protection of an $\mathrm{Ar}$ atmosphere. The synthetic process was carried out for $30 \mathrm{~min}$. Finally, the tube was allowed to cool to room temperature. The obtained samples are denoted CoP@FeZnP. Note that $\mathrm{NaH}_{2} \mathrm{PO}_{2}$ can decompose, readily generating poisonous $\mathrm{PH}_{3}$ in the process. For comparison, the $\mathrm{Co}_{3} \mathrm{O}_{4}$ nanocages and $\mathrm{Fe}-\mathrm{MOF}-5$ were also treated with the same phosphorization procedure. That is, the cobalt phosphide (denoted CoP) and Zn-Fe metal phosphide (denoted ZnFeP) were also synthesized. 


\subsection{Material characterization}

$\mathrm{X}$-ray diffraction (XRD) measurements were carried out on a Shimadzu XRD-6000 X-ray diffractometer using $\mathrm{Cu} \mathrm{K}_{\alpha}$ radiation. X-ray photoelectron spectra (XPS) were obtained on an Escalab 250Xi (Thermo Fisher Scientific) X-ray photoelectron spectrometer. The calibration of the binding energy was carried out by setting the binding energy of the $\mathrm{C} 1 \mathrm{~s}$ peak to 284.4 $\mathrm{eV}$. The transmission electron microscopy (TEM) images were obtained using a field-emission TEM (2100F, Japan) coupled with an energy-dispersive X-ray spectrometer (EDX) at an accelerating voltage of $200 \mathrm{kV}$. To prepare the specimens for TEM measurements, the as-grown substrates were immersed in 2 $\mathrm{mL}$ of ethanol and sonicated for $10 \mathrm{~s}$.

\subsection{Electrochemical measurements}

Catalyst suspensions in $1.0 \mathrm{~mL}$ of an ethanol/water $(v / v$ $=1: 5$ ) solution were prepared. In addition, $5 \mu \mathrm{L}$ Nafion solution (0.5 wt\%) was also added as a binder. For the electrode preparation, $10 \mu \mathrm{L}$ of the catalyst suspension $(10 \mathrm{mg} / \mathrm{mL})$ was dropped onto the surface of a pre-polished glassy carbon electrode (GCE). The electrocatalytic activities of the samples for the OER and HER were studied in $1 \mathrm{~mol} / \mathrm{L} \mathrm{KOH}$ solution and recorded on an Autolab potentiostat (Metrohm Autolab, Netherlands) at ambient temperature. All tests were performed in a three-electrode electrochemical cell with a saturated $\mathrm{Hg} / \mathrm{HgO}$ reference electrode and a graphite rod counter electrode. The prepared GCE electrodes were used as the working electrodes to investigate the electrocatalytic activities toward the HER and OER. Electrochemical impedance spectroscopy (EIS) was performed from $200 \mathrm{kHz}$ to $50 \mathrm{mHz}$ and analyzed by fitting the experimental results to equivalent circuits using the program NOVA 2.1. The double-layer capacitance $\left(C_{\mathrm{dl}}\right)$ of the hollow structures was obtained by applying cycle voltammograms over a range of scan rates $(20-180 \mathrm{mV} / \mathrm{s})$. The measurement system was calibrated against the reversible hydrogen electrode (RHE). The corresponding polarization curves were calibrated after $i R$ correction.

\section{Results and discussion}

\subsection{Characterization}

The design strategy for the preparation of the CoP@ZnFeP hierarchical hybrid is illustrated in Fig. 1. In a nutshell, three steps involving crystal growth, self-aggregation, and phosphorization were carried out. The TEM images show that the $\mathrm{Co}_{3} \mathrm{O}_{4}$ crystals have a well-defined hollow cubic structure with a uniform size distribution (ca. $120 \mathrm{~nm}$ ), as shown in Fig. 1b. The high-magnification TEM image (Fig. 1c) indicates that the nanocages have a porous surface and are composed of numerous nanoparticles. In the second step, the self-aggregation process was performed in a DMF/ethanol solution, and $\mathrm{Co}_{3} \mathrm{O}_{4} @ \mathrm{Fe}-\mathrm{MOF}-5$ hierarchical structures were obtained. The TEM shows that the Fe-MOF-5 nanotubes grow out from $\mathrm{Co}_{3} \mathrm{O}_{4}$ nanocage to form flower-like shapes. The $\mathrm{Co}_{3} \mathrm{O}_{4}$ nanocage is located at the center, and several Fe-MOF-5 nanotubes protrude like petals. As shown in Fig. $1 \mathrm{~d}$ and 1e, the Fe-MOF-5 nanotubes had a well-defined morphology with tube length of $400 \mathrm{~nm}$, diameter of $100 \mathrm{~nm}$, and shell thickness of 5-10 nm (Fig. S1, see the Supporting Information).

Furthermore, we noticed that the Fe-MOF-5 hollow nanotubes were only generated in the presence of the $\mathrm{Co}_{3} \mathrm{O}_{4}$ nanocages. In a control experiment performed under identical synthetic conditions but with no $\mathrm{Co}_{3} \mathrm{O}_{4}$ nanocages added, only irregular aggregates of Fe-MOF-5 particles formed (Fig. S2). Actually, the $\mathrm{Co}_{3} \mathrm{O}_{4}$ nanocage served as the surface for nucleation and could be a useful substrate for controlling the growth of the Fe-MOF-5 nanotubes. It was found that the morphology of the hybrids depends strongly on the amount of $\mathrm{Co}_{3} \mathrm{O}_{4}$. A detailed description of the morphological evolution of $\mathrm{Co}_{3} \mathrm{O}_{4} @ \mathrm{Fe}-\mathrm{MOF}-5$ has been reported by us previously [34]

Since most MOFs are nonconductive, MOFs have been rarely applied in the field of electrocatalysis [35,36]. In particular, to enhance the electrical conductivity of the $\mathrm{Co}_{3} \mathrm{O}_{4} @ \mathrm{Fe}-\mathrm{MOF}-5$ hierarchical structure, the $\mathrm{Co}_{3} \mathrm{O}_{4} @ \mathrm{Fe}-\mathrm{MOF}-5$ hybrids were generated by phosphorization via calcination. Typical TEM images show that the flower-like hollow structure was well maintained after calcination, and the nanotubes became highly porous, consisting of numerous nanocrystals (Fig. 2a and 2b). In particular, numerous nanocrystals filled the nanotubes, forming plentiful surface-active sites and increasing the surface area for the facile exchange of proton or oxygen-containing intermediates [37,38]. The high-resolution (HR)-TEM images (Fig. 2c and 2d) reveal that the phosphide nanoparticles have diameters of ca. $10 \mathrm{~nm}$. Additionally, elemental mapping was carried out to determine the distribution of $\mathrm{Zn}, \mathrm{Fe}$, and $\mathrm{P}$ in the nanotubes, and these measurements confirm the homogenous distribution (Fig. 2e). The corresponding EDX spectrum shows

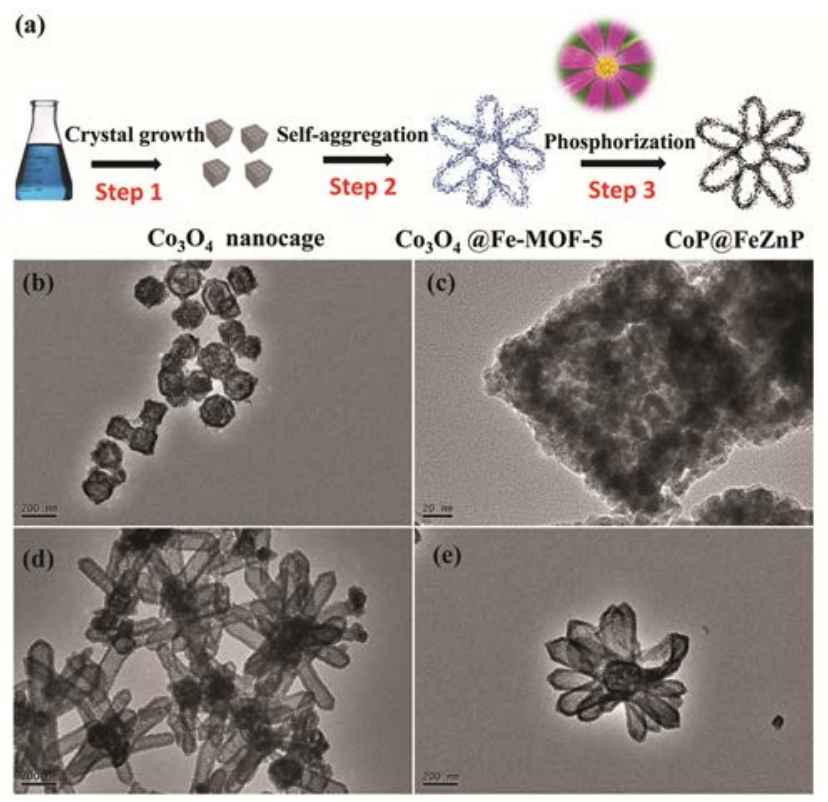

Fig. 1. (a) Schematic of the preparation of the CoP@ZnFeP hybrid. TEM images of the (b) $\mathrm{Co}_{3} \mathrm{O}_{4}$ nanocages and (c) magnification of one cage. (d) $\mathrm{Co}_{3} \mathrm{O}_{4} / \mathrm{Fe}-\mathrm{MOF}-5$ aggregates and (e) a typical hierarchical nanocomposite. 

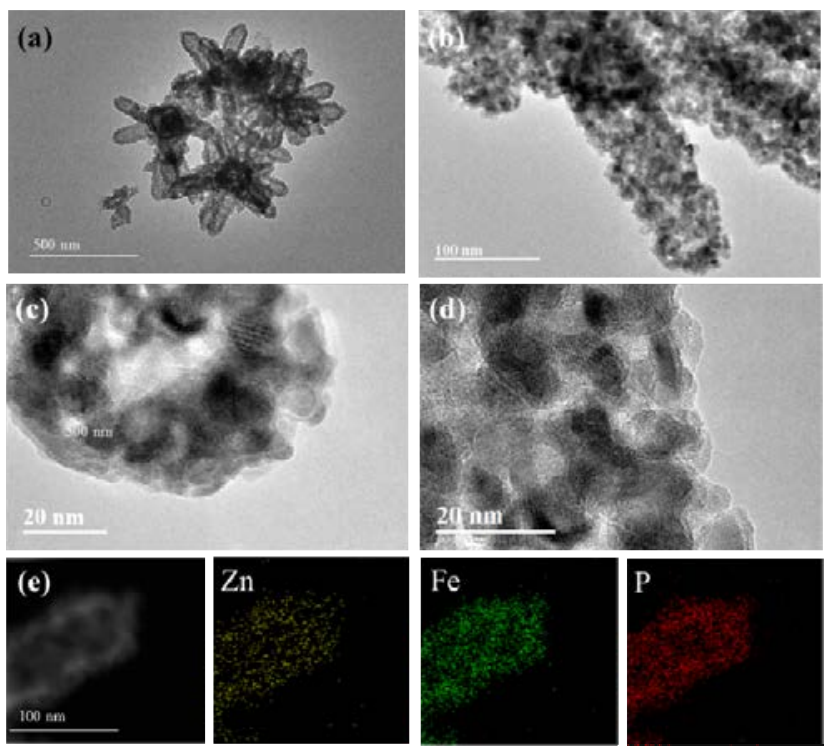

Fig. 2. (a) Low-magnification TEM image of the CoP@ZnFeP composite and (b) ZnFeP nanotubes. (c, d) HRTEM images of a typical ZnFeP nanotube composed of numerous nanocrystals. (e) TEM image and corresponding EDX elemental mapping.

that $\mathrm{Zn}, \mathrm{Fe}$, and $\mathrm{P}$ are present with an atomic ratio close to 1:2.5:4 (Fig. S3). We also measured the whole elemental composition of the CoP@ZnFeP hybrids, as shown in Fig. S4. In general, $\mathrm{Co}, \mathrm{Zn}, \mathrm{Fe}$, and $\mathrm{P}$ were detected, having an approximate molar ratio of $1: 1.1: 2.2: 5.7$. The chemical composition of the composites was further explored by XRD. A typical XRD pattern is shown in Fig. S5 and contains the main reflections from the CoP@ZnFeP hierarchical hybrid. The peaks at $26^{\circ}, 26.7^{\circ}$, and $31.4^{\circ}$ mainly originate from the $\mathrm{ZnP}_{2}$ phase and are matched

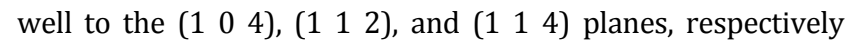
(JCPDF 24-1464) [39]. The peaks at $40.2^{\circ}$ and $44.1^{\circ}$ mainly originate from $\mathrm{Fe}_{2} \mathrm{P}$ and matched well with the (1 111 ) and $\left(\begin{array}{ll}2 & 0\end{array}\right.$ 1) planes, respectively (JCPDF 51-0943) [40,41]. All the other peaks are characteristic of $\mathrm{Co}_{2} \mathrm{P}$ (JCPDF 32-0306) and also matched well with the (1 $\left.2 \begin{array}{ll}1 & 1\end{array}\right)$ and (2 01 1) planes [42,43]. The results are consistent with the above-mentioned TEM analysis. The hierarchical CoP@ZnFeP nanocomposites were composed of numerous mixed nanocrystals.

Further insights into the valence and the surface chemical composition of CoP@ZnFeP were obtained through XPS measurements (Fig. 3). As shown in Fig. 3a, the Co $2 p$ core level spectrum showed two major peaks, assigned to Co $2 p_{3 / 2}$ and Co $2 p_{1 / 2}$, respectively [44-46]. The peak can be fitted with four peaks. The dominant peaks around 782.1 and $797.8 \mathrm{eV}$ were attributed to $\mathrm{Co}$ in $\mathrm{Co}_{2} \mathrm{P}$. Fig. $3 \mathrm{~b}$ shows the $\mathrm{Zn} 2 p$ core level XPS spectra [47]. The binding energy of the $\mathrm{Zn} 2 p_{3 / 2}$ peak was found at $1022.5 \mathrm{eV}$, and the other sharp peak at $1045.1 \mathrm{eV}$ corresponds to $\mathrm{Zn} 2 p_{1 / 2}$. The XPS spectrum of Fe $2 p$ core level spectrum can be deconvoluted into three main peaks (Fig. 3c). The peaks with binding energies of 711.2 and $714.1 \mathrm{eV}$ are assigned to $\mathrm{Fe}_{2} \mathrm{P}$ and, possibly, an Fe-based oxide. Another peak located at $724.5 \mathrm{eV}$ contributed to the related satellite peak $[48,49]$. The P $2 p$ spectrum (Fig. $3 d$ ) contains two peaks at 129.1 and $130.2 \mathrm{eV}$, which are assigned to $\mathrm{P} 2 p_{3 / 2}$ and $\mathrm{P} 2 p_{1 / 2}$, respectively. The two binding energies are attributed to the phosphorus anions of the metal phosphides. The broader peak at $135 \mathrm{eV}$ can be attributed to $\mathrm{P}-\mathrm{O}$ species and is close to the values reported previously. The presence of $\mathrm{O}$ may arise from the superficial oxidation of the CoP@ZnFeP particles as a result of air
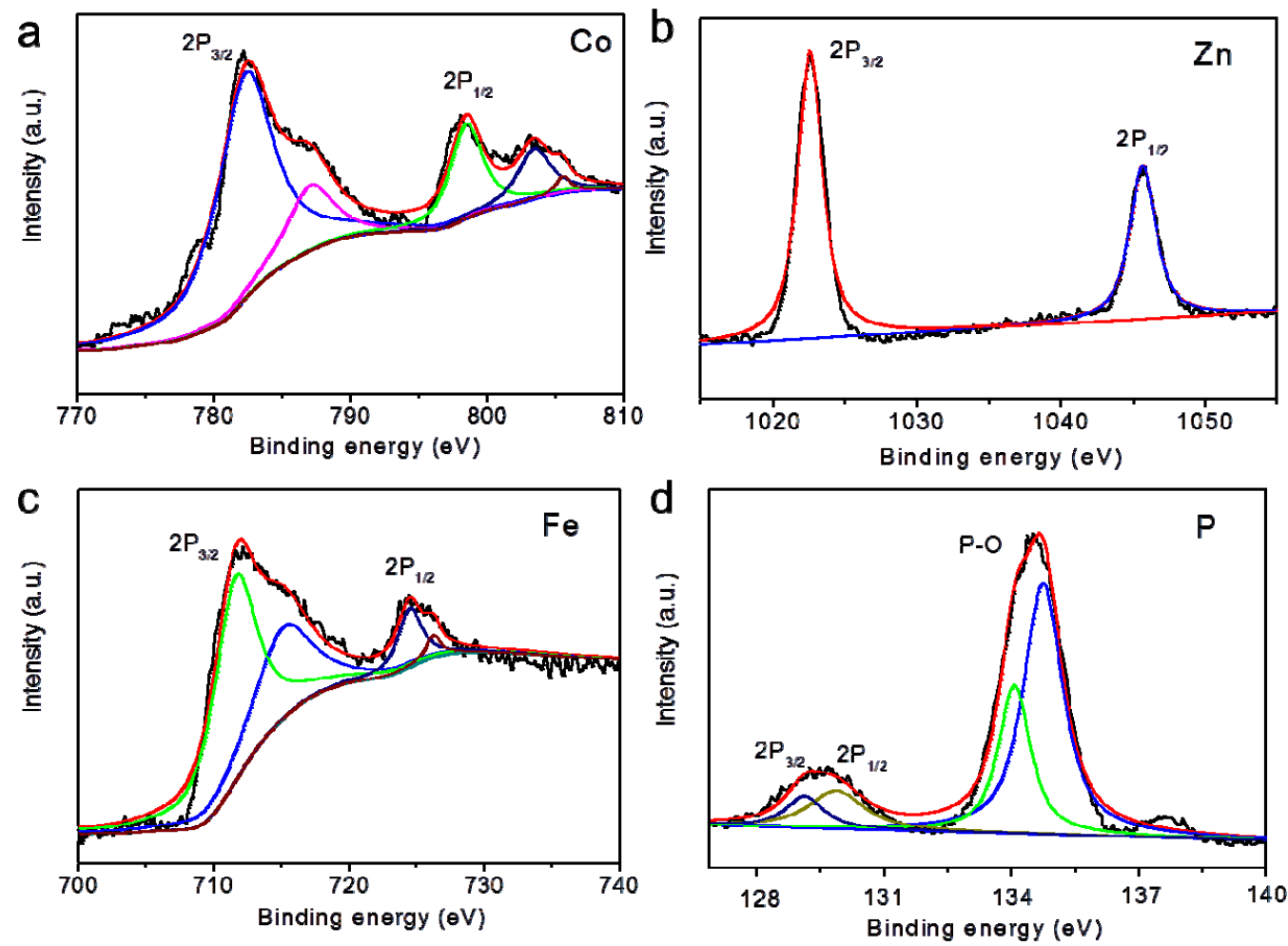

Fig. 3. (a) Co $2 p$, (b) Zn $2 p$, (c) Fe $2 p$, and (d) P $2 p$ XPS spectra. 
contact [50].

\subsection{Electrocatalytic activity}

The electrocatalytic HER activity of the CoP@ZnFeP hybrids was investigated in an alkaline electrolyte $(1.0 \mathrm{~mol} / \mathrm{L} \mathrm{KOH})$. The catalytic performance tests were conducted in a standard three-electrode system with a scan rate of $1.0 \mathrm{mV} / \mathrm{s}$ at room temperature. Fig. 4a shows the linear sweep voltammetry (LSV) curves of the CoP@ZnFeP hybrids, a mixture of CoP and $\mathrm{ZnFeP}$ (denoted CoP/ZnFeP), and commercial Pt/C (20\%). It is evident that the $20 \% \mathrm{Pt} / \mathrm{C}$ catalyst shows the best HER activity. The CoP@ZnFeP hybrids exhibited a high current density under a low applied overpotential, where the onset potential was close to $-50 \mathrm{mV}$ (vs. RHE). The CoP@ZnFeP hierarchical structure reached a current density of $-10 \mathrm{~mA} / \mathrm{cm}^{2}$ at a potential of $-148 \mathrm{mV}$ (vs. RHE). It is evident that the mixture of $\mathrm{Co}_{2} \mathrm{P}$ and ZnFeP (CoP/ZnFeP) showed inferior HER catalytic performance. The onset potential was close to $-100 \mathrm{mV}$ (vs. RHE) and the mixture required a larger potential of $-230 \mathrm{mV}$ (vs. RHE) to deliver a current density of $-10 \mathrm{~mA} / \mathrm{cm}^{2}$. The significant intrinsic activities of different samples determined the difference in the HER activities, which were revealed by comparing the Tafel slopes. As anticipated, the Tafel value of the CoP@ZnFeP hierarchical hybrid was $76 \mathrm{mV} /$ decade, which is lower than that of CoP/ZnFeP mixture (ca. $136 \mathrm{mV} /$ decade, Fig. 4b).

The electrocatalytic activities of the CoP@ZnFeP hierarchical hybrids for OER were also evaluated with a three-electrode electrochemical cell in $1.0 \mathrm{~mol} / \mathrm{L} \mathrm{KOH}$ solution. The polarization cures are shown in Fig. 4c. It was found that the CoP@ZnFeP hierarchical structure produced a small onset potential of $1.45 \mathrm{~V}$ (vs. RHE) and a high anode current density of $10 \mathrm{~mA} / \mathrm{cm}^{2}$ at a potential of $1.50 \mathrm{~V}$ (vs. RHE) and was superior to that of $\mathrm{IrO}_{2}$. In contrast, the mixture of $\mathrm{CoP}$ and $\mathrm{ZnFeP}$ (CoP/ZnFeP) exhibited a low current density under the same applied overpotential, where the onset potential was close to $160 \mathrm{mV}$ (vs. RHE). Meanwhile, the Tafel slope of the CoP@ZnFeP hierarchical structure catalyst was only 53.9 $\mathrm{mV} /$ decade, which is lower than that of $\mathrm{IrO}_{2}(60 \mathrm{mV} /$ decade $)$ and $\mathrm{CoP} / \mathrm{ZnFeP}$ (65.8 mV/decade), as shown in Fig. $4 \mathrm{~d}$. The results further indicate that the hierarchical structure showed superior OER catalytic performance compared to their bulk counterparts. Indeed, the HER and OER catalytic activity of the CoP@ZnFeP hierarchical structure is superior to most of the bifunctional electrocatalysts that have been reported in alkaline electrolytes (Table S1). The CoP@ZnFeP hierarchical structure was composed of different nano-building-blocks (nanoparticles, nanocages, and nanotubes), which yielded a large surface area and well-defined porous channels that are advantageous for mass and charge transport in an electrolyte. Previous research has indicated that only surface atoms or a very thin layer of the active electrode material plays a dominate role in the electrochemical reaction. Therefore, the hierarchical hollow structure results in more accessible active surface area for electrolyte permeation, which is beneficial for enhancing the catalytic activity [51]. The superior performance may also be attributed to the synergism between the different crystalline phases $\left(\mathrm{ZnP}_{2}, \mathrm{Co}_{2} \mathrm{P}\right.$, and $\left.\mathrm{Fe}_{2} \mathrm{P}\right)$. The results are also consistent with the scientific consensus that metal phosphides with complex metal compositions may improve the electrocatalytic ac-
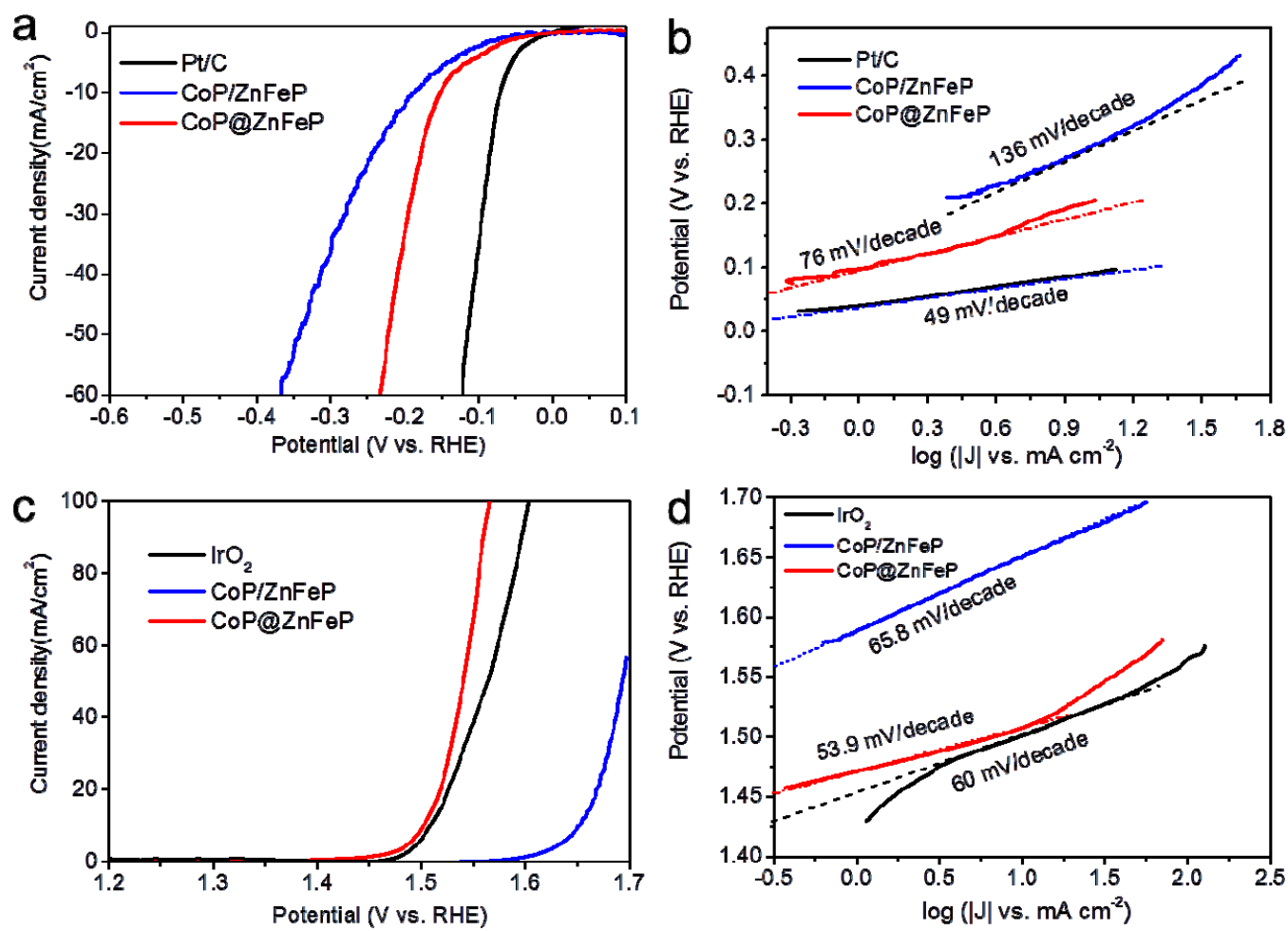

Fig. 4. (a, b) LSV and Tafel curves of the hollow CoP@ZnFeP hybrids, the mixture of CoP and ZnFeP (denoted CoP/ZnFeP), and the commercial Pt/C (20\%) samples for HER; (c, d) LSV and Tafel curves for OER. 
tivity [50,52].

We further investigated the electrode kinetics using double-layer capacitance $\left(C_{\mathrm{dl}}\right)$ and electrochemical impedance spectroscopy (EIS) measurements. As shown in Fig. S6A and $\mathrm{S6B}$, the $C_{\mathrm{dl}}$ values of the CoP@ZnFeP hierarchical structure were all higher than those of the mixture of $\mathrm{CoP}$ and $\mathrm{ZnFeP}$ (CoP/ZnFeP). Meanwhile, the EIS measurements showed the consistent order in charge-transfer resistance. As shown in Fig. S7, the EIS spectra show that the CoP@ZnFeP hybrid has a lower charge-transfer resistance, which results in faster OER and HER kinetics compared to that of the $\mathrm{CoP} / \mathrm{ZnFeP}$ catalyst. Specifically, the $C_{\mathrm{dl}}$ values and equivalent circuit diagrams are different when the same catalyst was used for HER and OER. The difference may be ascribed to two factors. First, the reaction mechanism of the OER is more complicated than that of the HER because of the greater number of reaction steps. Secondly, the different active sites for the OER and HER may also be responsible for these differences, as reported previously.

Next, we utilized the CoP@ZnFeP hierarchical structure as a bifunctional catalyst. For the measurement of the catalytic activity for the overall water splitting reaction, a two-electrode configuration was used, and the CoP@ZnFeP hierarchical material was used as the anode and the cathode. The overall water-splitting characteristics in a two-electrode configuration during 24-h continuous galvanostatic electrolysis are shown in Fig. S8. Remarkably, the CoP@ZnFeP hierarchical hybrids showed excellent activity, yielding a $10 \mathrm{~mA} / \mathrm{cm}^{2}$ water-splitting current on the application of a potential of just $1.6 \mathrm{~V}$ across the two electrodes. However, the potential changed by almost 70 $\mathrm{mV}$ over $24 \mathrm{~h}$. In addition, the formation of bubbles is an issue that cannot be ignored. During continuous galvanostatic electrolysis, hydrogen and oxygen bubbles were vigorously generated on the electrode surface. Most of the bubbles did not leave the electrode surface immediately, and these adherent bubbles reduced the effective active area, thus leading to an increase in the applied potential. Worse still, the catalysts had an extremely low adhesive force to the surface, leaving the surface with ease [53]. Finally but importantly, the TEM images show that the flower-like hierarchical structure was basically maintained after long-term electrochemical testing ( $24 \mathrm{~h}$ ), as shown in Fig. S9.

\section{Conclusions}

In summary, we report a stepwise strategy to design and fabricate novel hierarchically porous CoP@ZnFeP hollow nanocomposites. The as-prepared flower-like CoP@ZnFeP hybrids revealed remarkable electrocatalytic activity compared with the mechanical mixture of $\mathrm{CoP}$ and $\mathrm{ZnFeP}$. The excellent performance is mainly due to the nano-building-blocks, which showed a large surface area and well-defined porous channels, which are advantageous for mass and charge transport in the electrolyte. Our study shows the potential of these novel hierarchical structures to function as highly active, bifunctional electrocatalysts for the overall water splitting reaction. This design methodology may create opportunities to develop highly efficient and robust non-precious metal catalysts for applications in high performance energy conversion and storage devices, such as batteries, supercapacitors, and electrocatalysis.

\section{References}

[1] S. Chu, A. Majumdar, Nature, 2012, 488, 294-303.

[2] J. Luo, J. H. Im, M. T. Mayer, M. Schreier, M. K. Nazeeruddin, N. G. Park, S. D. Tilley, H. J. Fan, M. Grätzel, Science, 2014, 345, 1593-1596.

[3] R. Li, Chin. J. Catal., 2017, 38, 5-12.

[4] J. Chi, H. Yu, Chin. J. Catal., 2018, 39, 390-394.

[5] K. Zeng, D. Zhang, Prog. Energy Combust. Sci., 2010, 36, 307-326.

[6] M. Gong, D. Y. Wang, C. C. Chen, B. J. Hwang, H. Dai, Nano Res., 2016, 9, 28-46.

[7] F. Song, L. Bai, A. Moysiadou, S. Lee, C. Hu, L. Liardet, X. Hu, J. Am. Chem. Soc., 2018, 140, 7748-7759.

[8] S. Anantharaj, S. R. Ede, K. Sakthikumar, K. Karthick, S. Mishra, S. Kundu, ACS Catal., 2016, 6, 8069-8097.

[9] Z. Xiao, Y. Wang, Y. C. Huang, Z. Wei, C. L. Dong, J. Ma, S. Shen, Y. Li, S. Wang, Energy Environ. Sci., 2017, 10, 2563-2569.

[10] J. Liu, J. Wang, B. Zhang, Y. Ruan, L. Lv, X. Ji, K. Xu, L. Miao, J. Jiang, ACS Appl. Mater. Interfaces, 2017, 9, 15364-15372.

\section{Graphical Abstract}

Chin. J. Catal., 2019, 40: 1085-1092 doi: S1872-2067(19)63299-7

\section{Cobalt phosphide nanocage@ferric-zinc mixed-metal phosphide nanotube hierarchical nanocomposites for enhanced overall water splitting}

Xiaowei Hu, Yongheng Yin, Wei Liu, Xingwang Zhang*, Hongxiu Zhang* Linyi University; Zhejiang University

A novel hierarchical porous nanocomposite of a cobalt phosphide nanocage@ferric-zinc mixed-metal phosphide nanotube composite has been successfully fabricated using a self-assembly approach. The material shows enhanced catalytic activity for the hydrogen evolution reaction and oxygen evolution reaction compared to the bulk counterpart.

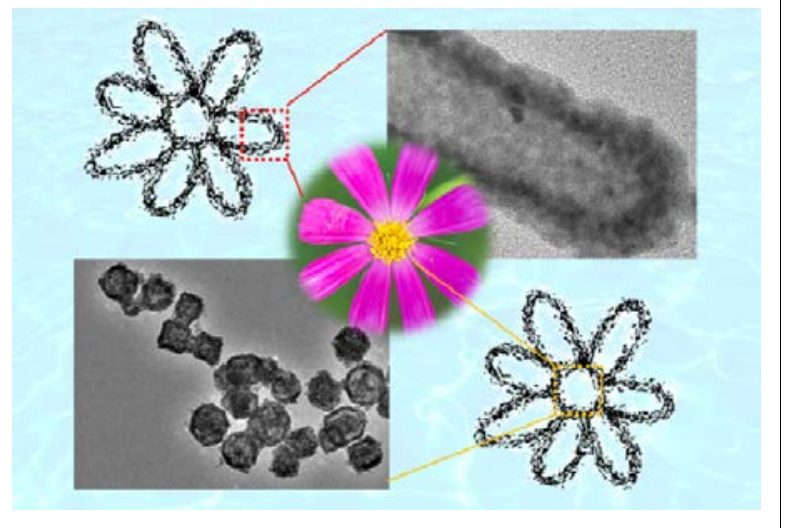


[11] Y. Yang, K. Zhang, H. Lin, X. Li, H. C. Chan, L. Yang, Q. Gao, ACS Catal., 2017, 7, 2357-2366.

[12] X. Gao, H. Zhang, Q. Li, X. Yu, Z. Hong, X. Zhang, C. Liang, Z. Lin, Angew. Chem. Int. Ed., 2016, 55, 6290-6294.

[13] Y. Jia, L. Zhang, G. Gao, H. Chen, B. Wang, J. Zhou, M. T. Soo, M. Hong, X. Yan, G. Qian, J. Zou, A. Du, X. Yao, Adv. Mater., 2017, 29, 1700017.

[14] W. Liu, H. Liu, L. Dang, H. Zhang, X. Wu, B. Yang, Z. Li, X. Zhang, L. Lei, S. Jin, Adv. Funct. Mater., 2017, 27, 1603904.

[15] D. Zhou, Z. Cai, X. Lei, W. Tian, Y. Bi, Y. Jia, N. Han, T. Gao, Q. Zhang, Y. Kuang, J. Pan, X. Sun, X. Duan, Adv. Energy Mater., 2018, 8, 1701905.

[16] P. Li, X. Duan, Y. Kuang, Y. Li, G. Zhang, W. Liu, X. Sun, Adv. Energy Mater., 2018, 8, 1703341.

[17] J. Jiang, Q. Liu, C. Zeng, L. Ai, J. Mater. Chem. A, 2017, 5, 16929-16935.

[18] Y. Wang, C. Xie, D. Liu, X. Huang, J. Huo, S. Wang, ACS Appl. Mater. Interfaces, 2016, 8, 18652-18657.

[19] N. Jiang, B. You, M. Sheng, Y. Sun, Angew. Chem. Int. Ed., 2015, 54, 6251-6254.

[20] M. Liu, J. Li, ACS Appl. Mater. Interfaces, 2016, 8, 2158-2165.

[21] Y. Li, H. Zhang, M. Jiang, Q. Zhang, P. He, X. Sun, Adv. Funct. Mater., 2017, 27, 1702513.

[22] F. Yu, H. Zhou, Y. Huang, J. Sun, F. Qin, J. Bao, W. A. Goddard III, S. Chen, Z. Ren, Nat. Commun., 2018, 9, 2551.

[23] Z. Liu, Y. Wang, R. Chen, C. Chen, H. Yang, J. Ma, Y. Li, S. Wang, J. Power Sources, 2018, 403, 90-96.

[24] Y. Zheng, Y. Jiao, M. Jaroniec, Y. Jin, S. Z. Qiao, Small, 2012, 8, 3550-3566.

[25] S. L. James, Chem. Soc. Rev., 2003, 32, 276-288.

[26] L. Tao, C. Y. Lin, S. Dou, S. Feng, D. Chen, D. Liu, J. Huo, Z. Xia, S. Wang, Nano Energy, 2017, 41, 417-425.

[27] H. Furukawa, K. E. Cordova, M. O'keeffe, O. M. Yaghi, Science, 2013, $341,1230444$.

[28] A. U. Czaja, N. Trukhan, U. Müller, Chem. Soc. Rev., 2009, 38, 1284-1293.

[29] B. Yilmaz, N. Trukhan, U. Müller, Chin. J. Catal., 2012, 33, 3-10.

[30] J. Lee, O. K. Farha, J. Roberts, K. A. Scheidt, S. T. Nguyen, J. T. Hupp, Chem. Soc. Rev., 2009, 38, 1450-1459.

[31] W. Xia, A. Mahmood, R. Zou, Q. Xu, Energy Environ. Sci., 2015, 8, 1837-1866.
[32] A. Corma, H. García, F. Llabrés I Xamena, Chem. Rev., 2010, 110, 4606-4655.

[33] L. Hu, N. Yan, Q. Chen, P. Zhang, H. Zhong, X. Zheng, Y. Li, X. Hu, Chem. Eur. J., 2012, 18, 8971-8977.

[34] X. W. Hu, S. Liu, B. T. Qu, X. Z. You, ACS Appl. Mater. Interfaces, 2015, 7, 9972-9981.

[35] K. M. Choi, H. M. Jeong, J. H. Park, Y. B. Zhang, J. K. Kang, O. M. Yaghi, ACS Nano, 2014, 8, 7451-7457.

[36] L. Wang, Y. Han, X. Feng, J. Zhou, P. Qi, B. Wang, Coord. Chem. Rev., 2016, 307, 361-381.

[37] X. Liu, D. Wang, Y. Li, Nano Today, 2012, 7, 448-466.

[38] M. A. Boles, D. Ling, T. Hyeon, D. V. Talapin, Nat. Mater., 2016, 15, 141-153.

[39] H. Hwang, M. G. Kim, Y. Kim, S. W. Martin, J. Cho, J. Mater. Chem. A, 2007, 17, 3161-3166.

[40] Y. Yuan, H. Pei, H. Chen, L. Zuo, J. Shen, Catal. Commun., 2017, 100, 202-205.

[41] M. Zhang, H. Wang, Q. Li, J. Feng, Y. Chai, R. Yuan, X. Yang, Appl. Surf. Sci., 2018, 453, 56-62.

[42] S. Liu, Y. Qian, X. Ma, Mater. Lett., 2008, 62, 11-14.

[43] M. Chen, W. Zhou, M. Qi, J. Yin, X. Xia, Q. Chen, J. Power Sources, 2017, 342, 964-969.

[44] H. Zhang, B. Yang, X. Wu, Z. Li, L. Lei, X. Zhang, ACS Appl. Mater. Interfaces, 2015, 7, 1772-1779.

[45] J. F. Callejas, C. G. Read, E. J. Popczun, J. M. Mcenaney, R. E. Schaak, Chem. Mater, 2015, 27, 3769-3774.

[46] L. Huang, R. Chen, C. Xie, C. Chen, Y. Wang, Y. Zeng, D. Chen, S. Wang, Nanoscale, 2018, 10, 13638-13644.

[47] K. H. Le Ho, L. Rivier, B. Jousselme, P. Jégou, A. Filoramo, S. Campidelli, Chem. Commun., 2010, 46, 8731-8733.

[48] P. Jiang, Q. Liu, Y. Liang, J. Tian, A. M. Asiri, X. Sun, Angew. Chem. Int. Ed., 2014, 53, 12855-12859.

[49] C. Y. Son, I. H. Kwak, Y. R. Lim, J. Park, Chem. Commun., 2016, 52, 2819-2822.

[50] P. He, X. Y. Yu, X. W. D. Lou, Angew. Chem. Int. Ed., 2017, 56, 3897-3900.

[51] C. M. Parlett, K. Wilson, A. F. Lee, Chem. Soc. Rev., 2013, 42, 3876-3893.

[52] Y. Feng, X. Y. Yu, U. Paik, Chem. Commun., 2016, 52, 1633-1636.

[53] X. Zou, Y. Zhang, Chem. Soc. Rev., 2015, 44, 5148-5180.

\title{
磷化钴@铁-锌双金属磷化物多级纳米复合物的制备及其电催化水分解性能
}

\author{
胡晓炜 ${ }^{\mathrm{a}}$ ，尹永恒 ${ }^{\mathrm{a}}$, 刘 伟 ${ }^{\mathrm{a}}$, 张兴旺, ${ }^{\mathrm{b}}{ }^{*}$, 张红秀 ${ }^{\mathrm{a}, \#}$ \\ 旧沂大学化学化工学院, 功能纳米材料与技术山东省高校重点实验室, 山东临沂276005

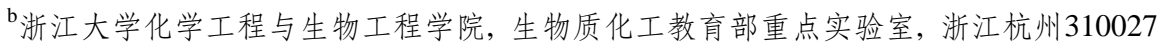

\begin{abstract}
摘要: 氢能源因其储量丰富、高效、零污染等特性而受到广泛关注. 电解水产氢作为一种有效的获取氢能源的方式成为当 前研究的重点. 但由于电极表面反应过电势的存在极大增加了电解水的能耗, 因此需要开发高效的电催化材料以提高电 解水反应动力学. 考虑到实际应用, 设计和构筑在同一电解液中同时具有高效催化产氢和释氧能力的双功能催化材料更 为重要且更具挑战. 目前, 越来越多的非贵金属基双功能催化材料被开发和报道, 比如过渡金属硫化物、氧化物、层状双 金属氢氧化物、碳化物、氮化物和磷化物等, 其中又以磷化物的研究更为广泛. 金属有机骨架化合物(MOFs)因其具有独特 的性能(孔隙率高、超高比表面积、可调控的化学组分和孔道结构等)在能源转化等领域得到广泛应用. 但是, 基于MOFs 材料转化的多组分过渡金属磷化物应用于全分解水体系的报道还比较少. 先前的研究表明, 优化催化材料的微纳结构和 化学组成是提高材料催化性能的关键. 我们利用三步法(晶体生长、自组装和磷化)设计并制备了一种基于MOFs转化的新 型分级纳米复合材料CoP@ZnFeP.
\end{abstract}


透射电子显微镜(TEM)结果显示, 自组装形成的花状 $\mathrm{Co}_{3} \mathrm{O}_{4} @ \mathrm{Fe}-\mathrm{MOF}-5$ 中空结构在磷化后形貌能够很好地保持. X射 线衍射(XRD)表明, $\mathrm{CoP} @ \mathrm{ZnFeP}$ 纳米复合物是由大量的混合纳米晶体组成, 主要包括 $\mathrm{Co}_{2} \mathrm{P}, \mathrm{ZnP}_{2}$ 和 $\mathrm{Fe}_{2} \mathrm{P}$. 在碱性 $(1.0 \mathrm{~mol} / \mathrm{L}$ $\mathrm{KOH}$ )条件下, CoP@ZnFeP纳米复合物表现出优异的催化产氢(HER)和释氧(OER)性能, 其释氢和产氧的启动电位分别为 -50 和 $148 \mathrm{mV}$ (vs. RHE), 相应的Tafel斜率分别为76和 $53.9 \mathrm{mV} / \mathrm{dec}$ de. 优异的电催化性能主要归功于复合材料的多级纳米 结构组元 (纳米粒子、纳米笼和纳米管), 其有序的多孔结构和大的比表面积有利于电解液的渗透、气体的扩散和电子的转 移. 作为对比, 我们利用相似方法制备了 $\mathrm{CoP}$ 和ZnFeP纳米粒子的机械混合物 (CoP/ZnFeP). 测试数据表明, CoP@ZnFeP分 级复合材料的催化性能优于 $\mathrm{CoP} / \mathrm{ZnFeP}$ 机械混合物. 鉴于 $\mathrm{CoP} @ Z n F e P$ 复合材料优异的催化性能, 我们将其应用于全分解 水体系. 在两电极体系中, 达到 $10 \mathrm{~mA} / \mathrm{cm}^{2}$ 电流密度仅需1.6 V电压, 表明材料具有优异的全分解水性能. 同时该复合物也 显示出较好的稳定性, 经过 $24 \mathrm{~h}$ 连续水解后, 电解电位仅升高70 mV. 但同时我们也注意到电极表面剧烈产生的气泡会对 电极材料的稳定性有严重影响. 此项研究可为设计高效的非贵金属催化材料应用于能源转化和储存等领域提供较好的思 路和借鉴.

关键词: 多级结构; 磷化物; 电催化; CoP@ZnFeP; 水分解

收稿日期: 2018-11-29. 接受日期: 2019-01-09. 出版日期: 2019-07-05.

*通讯联系人. 电话/传真: (0571)87952525; 电子信箱: xwzhang@zju.edu.cn

\#通讯联系人. 电话/传真: (0539)7258620; 电子信箱: zhanghongxiu@lyu.edu.cn

基金来源：山东省自然科学基金(ZR2018BB061, ZR2018BB060, ZR2018LB004).

本文的电子版全文由Elsevier出版社在ScienceDirect上出版(http://www.sciencedirect.com/science/journal/18722067). 